\title{
C05945
}

\section{Construction Workers' Well-Being: What Leads to Depression, Anxiety, and Stress?}

\author{
Rebecca R. Langdon ${ }^{1}$ and Sukanlaya Sawang ${ }^{2}$
}

\begin{abstract}
Work-related stress is an important issue in any industry, particularly for construction workers where stressful environments are frequently encountered. Critical questions are therefore: what are the primary stressors in the construction work-place; and what are the relationships between the strain effect of psychological distress and the counter-measures and coping mechanisms used by construction workers? The first question was addressed using Qmethodology survey with 18 participants. The results show that time and personal finance, and the task nature of the work, are important stressors. For the second question, a questionnaire survey administered to 91 participants on two construction sites of a single contractor was used to collect data about the stressors, psychological strain effects and coping strategies they used. Mediated regression analysis of the data showed that lack of personal and family time, increases in the cost of living, and fears about job security all act as powerful stressors. Coping strategies including acceptance, self-blame, and disengagement are associated with higher levels of psychological distress. Increased substance use, while associated with lower levels of anxiety, may only be a short term coping mechanism. An anomaly was found with humour as a coping strategy, where the relationship was found to be counter-intuitive and contrary to the findings of previous research. Future research should examine this more closely. Employers should better inform workers about the negative effects of maladaptive coping strategies, and offer opportunities for adopting more positive alternatives.
\end{abstract}

\footnotetext{
${ }^{1}$ Queensland University of Technology, Australia

${ }^{2}$ Coventry University, U.K. and Queensland University of Technology, Australia
} 
Keywords: construction workers; coping; mental health; stressors; work-life demands

The construction industry is recognized as Australia's third largest source of labor employment with a workforce estimated at approximately 1,046,900 workers (Australian Bureau of Statistics, 2015). Due to its high rate of employment and male participation the construction industry subsequently has a high rate of suicide (Milner, Niven, \& LaMontagne, 2014). Recently, the non-construction industry suicide rate was reported at 13.4 per 100,000 while the construction industry suicide rate was 24.6 (Milner, 2016). Furthermore, during 2012 Australia reported 169 confirmed cases of suicide where the primary employment type was listed as construction (Doran, Ling, \& Milner, 2015). During that same year, Australia recorded 30 construction-related workplace fatalities (Safe Work Australia, 2013). This suggests Australian construction workers are 5.6 times more likely to die from suicide, than to die from a work-related illness or injury.

The mental health conditions such as stress, depression and anxiety have the potential to lead to suicidal thoughts among individuals (Vilhjalmsson, Sveinbjarnardottir, \& Kristjansdottir, 1998). Drawing from workers compensation data it was revealed that $21.5 \%$ of Australian construction workers, compared to $17.5 \%$ of the general adult population, was impacted by a mental health condition (including affective disorders, anxiety or substance use disorders) within a 12 month period (Pricewaterhousecoopers, 2014). A government inquiry into the suicide cases in construction workers has raised an awareness for industry to provide an agency-based intervention for workers. This intervention includes awareness training (to identify suicidality in at-risk co-workers), referral systems to third party assistance or counselors, and intervention systems using the safeTALK model, i.e.Tell, Ask, Listen, KeepSafe — to engage persons with thoughts of suicide and to connect them to life-affirming resources (Gullestrup, Lequertier, \& Martin, 2011; LivingWorks, 2015). These interventions 
are a good start for the construction industry, though they are initially targeted as training to identify suicide risk and intervene in the final stages of suicide ideation, rather than addressing some of the potential factors precipitating suicide.

Contributing factors to suicide can include work and/or non-work related issues, which lead to mental health conditions such as depression, anxiety and stress. Long-term exposures to these mental health conditions are likely to lead to suicide ideation. Therefore, it is important to understand the relationships of coping mechanisms which are adopted in response to those stressors. To date, these relationships have been explored for construction professionals nationally and internationally (Dhar, 2011; Haynes \& Love, 2004; Leung, Chan, \& Olomolaiye, 2008). For construction research, a gap exists where the stress, coping, and psychological outcomes relationship is yet to be fully explored for the labor workforce, with existing literature calling for more comprehensive mental health research for these workers (Dhar, 2011; Jacobsen et al., 2013; Lingard \& Turner, 2015). This study thus aims to further unpack the processes in relation to stressors, coping and mental health for the construction labor workforce. More specifically, the study aims to answer the following Research Questions (RQs):

RQ1: Which daily stressors do Australian construction workers consider as their primary sources of stress?

RQ2: What is the relationship between daily stressors, coping strategy adopted and psychological outcomes (depression, anxiety and stress) for construction workers?

This study will contribute to the existing knowledge four in ways. First, it proposes the daily stressors that are most relevant to the construction workers context. Existing organizational research identifies general work stressors which include: time pressures, role ambiguity, work overload, and poor communication (Beehr \& Glazer, 2005). However, 
international literature suggests that other stressors (such as safety) are more relevant to construction workers (Leung, Chan, \& Cooper, 2015).

Second, the current study employs Q methodology (Study 1) as a novel method in construction and wellbeing research to explore the attitudinal related construct of stress. Instead of using solely qualitative or quantitative methods, Q methodology is a mixed method. Using qualitative judgments to define problems and to develop statements which reflect participants’ perspectives, statements are then sorted and quantitatively analyzed. This Q approach is uncommon in construction research, so far a handful of studies exist using Q method to explore work-life demands among construction personnel. One of the studies did not explicitly state if the participants were professionals or tradesmen (Turner, 2013), and the other detailed work-health safety perceptions rather than stressors (Zhang, Lingard, Blismas, et al., 2014). Zhang et al.’s (2014) study focused on safety aspects by using 10 photographs representing different building systems/construction technologies. Turner's study, on the other hand, examined psychological aspects of work-life demands and concluded that work and personal demands did not operate in separate spheres. The question remains of which domain should first be targeted (or provided support) by an organization. The current study thus attempts to unpack this aspect by using the Q method to explore the common and primary demands/stressors among tradesmen (skilled and non-skilled) on two construction sites.

Third, the current study also proposes to elucidate on the coping patterns adopted by construction workers and their relationship with their mental health (for Study 2 using survey method). Understanding common coping mechanisms among construction workers may shed some light on the extent of different coping behaviors which may lead to positive or negative psychological outcomes. For example, substance use (reported to be high in construction workers) can lead to negative behaviors such as suicide attempts (Australian Institute for 
Suicide Research and Prevention, 2006; Iacuone, 2005; Vijayakumar, Kumar, \& Vijayakumar, 2011; Vilhjalmsson et al., 1998).

Fourth, there are very few studies that focus on the mental health of construction workers. Of the existing studies, these focus on the non-labor workforce, for example project managers (Haynes \& Love, 2004; Leung, Chan, \& Olomolaiye, 2008); engineers (Leung, Chan, Chong, \& Sham, 2008); and other construction managers/professionals (Bowen, Edwards, \& Lingard, 2013; Bowen, Govender, Edwards, \& Cattell, 2014; Love, Edwards, \& Irani, 2010). Furthermore, construction labor studies often explore different outcome variables such as the impacts of worker stress on safety (Goldenhar, Williams, \& Swanson, 2003; Leung, Chan, \& Yu, 2012), construction worker general health (Lingard \& Turner, 2015) and the association between psychological distress and an increased prevalence for work-related injuries (Jacobsen et al., 2013).

To date, there have been no studies examining the predictors for depression, anxiety and stress for commercial-residential construction workers in Australia. These psychological constructs are critical, as they can contribute to suicide, of which construction workers are highly represented in these statistics (Milner et al., 2014; Vilhjalmsson et al., 1998). This study will expand the current knowledge by examining the role of stressors and coping and, their impact on these psychological constructs. This will allow for the understanding of (a) the types of occupational related stressors that highly impact on individuals; (b) their coping patterns and (c) the effectiveness of the stress-coping mechanisms selected by construction workers.

The remainder of this paper is organized as follows: A review of the stress theories, particularly Lazarus's Transactional Model of Stress (TMS) as a framework for the study is presented. This is followed by a review of the mediation process of coping in order to assist with managing psychological outcomes (specifically stress, depression and anxiety). Finally a 
review of the existing mental health literature on construction workers is evaluated. As there is limited research focusing directly on the labor workforce, examination of studies involving construction professionals (where appropriate) is reviewed.

\section{Stressors and Stress Theories}

\section{Stressors}

Stress (or stressors) are defined as any internal or external demand which impacts on behavior, functioning and performance (Jamal, 1984; Muse, Harris, \& Feild, 2003). Thoits (1995) suggested there are three broad categories of stressors which include life events, chronic strains, and daily stressors. Life event stressors are described as acute events (e.g. divorce) resulting in the need for short-term behavioral adjustments. Chronic strains are described as persistent and prolonged events (e.g. chronic injury) requiring continual readjustments. Daily stressors are described as daily mini-events (e.g. traffic jams) which require temporary behavioral adjustments (Thoits, 1995).

An accumulated body of research has documented the impacts of stress on both psychological and physical health (Thoits, 1995). For example, a meta-analysis on the impacts of life event stressors (e.g. divorce, bereavement) was found to be associated with lowered immune functioning and health implications (Herbert \& Cohen, 1993). Chronic strains on a range of health conditions (e.g. multiple sclerosis and spinal cord injuries) were found to be associated with severe negative psychological and physical outcomes (Dijkers, 1997; Mohr, Hart, Julian, Cox, \& Pelletier, 2004). This research has been followed by an equally large number of studies investigating the impacts of various mediators and moderators impacting on stress and wellbeing, including coping (Carver et al., 1993; Meyer, 2001), personality (Connor-Smith \& Flachsbart, 2007) and locus of control (Cheng, Cheung, Chio, \& Chan, 2013). 
As research progresses in the field of stress and wellbeing, more emphasis is being placed on understanding the unique, or individual stressors for a particular demographic or study population (Sawang, Oei, Goh, et al, 2010). This allows for a more comprehensive understanding of not only events that may be shared (such as divorce, or chronic illness), but also specific daily stressors contributing to the experience of distress or harm. Therefore, this study will explore the impact of daily stressors specific to Australian construction laborers. Stressors were selected as the focus, as the unique stressors faced by this workforce are yet to be explored in Australian workers. The Australian Institute for Suicide Research and Prevention (2006) reported a range of work and interpersonal factors for the construction industry to address stemming from focus groups conducted. This included length of hours, substance use, job security, lack of recreation time, and financial pressures. This study used a small sample and it was also acknowledged by the researchers that these themes and further in-depth investigations into the mental health of construction workers was needed to help address suicide in the construction industry (Australian Institute for Suicide Research and Prevention, 2006; Doran et al., 2015; Milner et al., 2014).

\section{Stress Theories}

Stress theories belong broadly to either the systemic or psychological perspectives (Krohne, 2001). Systemic stress, described by Selye (1950) focuses on the biological changes due to a predictable response pattern. This is known as the General Adaptation Syndrome (GAS). Arguments against Selye's GAS theory include the inability for a cognitive appraisal of the threat to determine its significance, relevance or importance to a persons’ survival (Krohne, 2001; Lazarus, 1993). This led to the psychological perspectives on stress. Here, there are two separate concepts - appraisal and coping. According to Lazarus and Folkman (1984) the appraisal stage includes a primary and secondary appraisal. Primary appraisal establishes the significance of the stressor as irrelevant, benign-positive or stressful. 
Once the initial appraisal has been established, the secondary event involves an appraisal of the person's resources available to manage the stressor. If the primary appraisal is stressful, and the secondary appraisal reveals there are no suitable resources available, the person will perceive stress (Lazarus \& Folkman, 1984, 1987).

\section{Coping With Stress: The Microanalytic Perspective}

Microanalytic perspectives focus on the coping processes and mechanisms adopted in stressful situations generally favoring state-related outcomes (Krohne, 1996; Smith \& Wallston, 1997). This perspective seeks to best understand the process of coping, the changes in coping over situations for people and, consistent applications of particular coping strategies adopted in response to particular stressors.

Lazarus and Folkman $(1984,1987)$ described coping as the changing efforts, both cognitive and behavioral, to manage events that have been appraised as stressful. They posited two particular coping styles in response to managing the situation, problem-focused coping and emotion-focused coping. A problem-focused style is more behavioral, taking measures to identify, define and solve the problem in a pragmatic approach. Emotionfocused styles were described as the cognitive efforts to minimize the distress such as denial or venting (Lazarus \& Folkman, 1984, 1987). Initially, emotion-focused strategies were labeled as ineffective, however research suggested that some forms of emotion-focused coping may be beneficial (Baker \& Berenbaum, 2007). For example, participants asked to write about their emotions during stressful situations benefited from and increased awareness and expression of their emotions. It was assumed that awareness of emotions could influence (and change) a person's mood (Baker \& Berenbaum, 2007). It appears this awareness had a positive outcome for the cognitive appraisal of the stressful situation.

Investigating stressors, coping mechanisms and psychological outcomes in construction professionals in South Africa, Bowen, Edwards, Lingard, and Cattell (2014) used an 
exploratory method on four professions (architects, engineers, quantity surveyors and construction managers). Participants were asked to rate their stress levels and report on a range of psychological, physiological and sociological effects. Qualitative data was also used to determine coping mechanisms, in addition to measures on alcohol use and substance use (Bowen, Edwards, et al., 2014). More than half (55\%) of construction professionals reported a stress level of seven or higher (scale 1-10). Not being appreciated by work colleagues was reported as the highest psychological outcome, followed by feeling tense. The highest physiological outcome was reported as disturbances to sleep, followed by difficulty relaxing. Sociological outcomes was highest for strain on social activities, followed by strain on social relationships (Bowen, Edwards, et al., 2014).

In assessing their coping mechanisms, a range of active coping strategies were reported from exercise, recreational activities, and meditation. Alcohol use was reported to be highest for construction managers, with approximately one third (30\%) consuming 120g (ten units) of alcohol per week. Eighty per cent of professionals consumed less than ten units per week (Bowen, Edwards, et al., 2014). A low proportion of professionals reported engaging in substance use, architects (5\%), engineers (4\%), quantity surveyors (4\%) and construction managers (2\%). This study explored the issues such as stress and outcomes and prevalence of each of these constructs on the four construction professions described, however they did not directly test the relationships between these variables to indicate which stressors were more (or less) likely to lead to psychological, physiological or sociological outcomes (Bowen, Edwards, et al., 2014). Furthermore, due its exploratory nature, empirically valid measures of these constructs were not used, and is a limitation to this study.

Studies investigating construction worker coping and their relationship with mental health were explored for construction project managers by Haynes and Love (2004) using the Ways of Coping scale (S. Folkman \& Lazarus, 1988) and the Depression Stress Anxiety scale 
(DASS) (S. H. Lovibond \& Lovibond, 1995). Predictors for depression included high avoidance coping, and low active coping strategies. Predictors of anxiety included high social coping (such as seeking social support from others), high cognitive avoidance coping, high acceptance of responsibility, and low active coping. Predictors of stress included high social coping, high self-control, and low active coping. Haynes and Love (2004) used a small sample $(N=99)$ of all male project managers. The study provides insight into the relationships between stressors, coping and psychological outcomes (depression, stress, anxiety) for professionals. Follow-up studies have yet to be conducted to determine if adjustments can be made to improve these relationships for construction professionals. For example, can depression in this cohort now be reduced by promoting skills to identify and reduce avoidance coping and increasing active coping? For laborers, it is difficult to determine if these stressors, and their relationships will be the same, highlighting a need for research in this area.

Construction laborers in India who experienced high stressors such as physically demanding tasks and high workload, were reported to experience higher amounts of stress. Adaptive coping mechanisms (such as engaging in leisure) was reported to reduce feelings of stress (Dhar, 2011). However this study used qualitative data, with no direct testing of these relationships and, was conducted on low-income construction workers. According to the Australian Bureau of Statistics, construction workers were the second highest non-managerial employee wage earners in Australia (Australian Bureau of Statistics, 2012). This indicates that further exploration of these relationships for Australian workers is needed to understand their implications on the Australian workforce. As coping and coping patterns are yet to be explored in the construction labor workforce, this research will seek to explore the coping patterns that are predictive of poor mental health in order for future research to design and implement measures to reduce them. 


\section{Determinants of Depression, Anxiety and Stress}

The prolonged effects of stress on physical, psychological and behavioral outcomes is well documented. For example, when the stress-response system is activated for prolonged periods of time without effective resolution or coping, the physiological heightened alert response can lead to various cardiovascular, immune and metabolic diseases in addition cognitive declines in memory, learning and functioning (McEwen, 1998). Further implications include poor psychological health, depression, instances of suicide ideation and increases in substance abuse for coping (Wilhelm, Kovess, Rios-Seidel, \& Finch, 2004).

In the study previously mentioned on construction managers coping and stress outcomes, Haynes and Love (2004) reported that despite managers experiencing similar stressors, those managers with adaptive coping strategies such as actively doing something about the situation, reported better psychological outcomes than those that engaged in maladaptive strategies such as avoidance. This relationship is observed across many studies, including non-clinical samples such as young adults adjusting to life transitions $(N=89)$ where positive coping strategies significantly reduced feelings of stress and depression (Brissette, Scheier, \& Carver, 2002). In addition to clinical samples such as a longitudinal study of men diagnosed with human immunodeficiency virus $(N=425)$ where poor coping significantly accounted for an additional $10 \%$ of variance in depressive mood (Susan Folkman, Chesney, Pollack, \& Coates, 1993).

The important information extracted from these research findings allows for the identification of unique stressors and coping styles adopted for these situations, which in turn, assists for the intervention for (a) reducing stressors predicted to increase poor psychological health, and (b) promoting positive coping strategies for those stressors upon which employees are typically engaging in maladaptive coping (Haynes \& Love, 2004). Therefore, in an industry heightened by high suicide risk, understanding these stressors, their coping 
responses and their psychological outcomes, becomes an important first step in assisting in the prevention of suicide and poor psychological wellbeing.

\section{Hypothesis Development}

To assess the relevance of stressors for construction workers, Leung et al. (2015) developed and implemented a 60-item questionnaire designed to investigate different types of stressors. They found inadequate safety equipment was rated the highest, followed by poor site environment, and organizational formalization (a heavy focus on rules, policies processes and procedures). Though Leung et al. (2015) provide insight into stressors relevant to the construction industry, it needs to be highlighted previous studies used non-labor workers such as professional cost estimators and engineers (Leung, Chan, Chong, et al., 2008; Leung, Sham, \& Chan, 2007; Leung, Skitmore, \& Chan, 2007), project managers (Leung, Chan, \& Olomolaiye, 2008; Yung, Chan, \& Yu, 2009) or, they did not indicate the labor type in their findings related to construction workers (Leung et al., 2015).

Additionally, studies on construction workers conducted by Leung et al. (2015) were undertaken in Hong Kong also raises important implications, particularly when outcomes related to stress where workers rated safety and inadequate safety equipment as their primary concern (Leung et al., 2012; Leung, Chan, \& Yuen, 2010). Differences in standards in construction practices and safety vary considerably between Hong Kong and Australia will need to be taken into account. For example, bamboo scaffolding which is listed as a trade in many of the Leung studies, is considered an acceptable practice in Hong Kong, yet is considered unsafe and dangerous in Australia and other countries (Petrick \& Rinefort, 2004). This raises important implications if the stressors identified as important for this subset of workers, applies to construction workers in Australia. Accordingly, the first study in this paper is designed to explore the stressors identified by Leung et al. (2015) and determine if 
any adjustments should be made to further develop stressors specific to construction workers in Australia.

The first study is designed to understand which daily stressors are considered primary concerns among construction workers. The research question is:

RQ1: Drawing from existing literature, what stressors will be perceived as primary concerns by Australian construction workers? (Study 1).

Theoretical categories of coping labeled as helpful (adaptive) have been associated with positive outcomes, while categories of coping labeled as harmful (maladaptive) have been associated with negative outcomes (Chronister, Johnson, \& Lin, 2014; Skinner, Edge, Altman, \& Sherwood, 2003). Research across clinical and non-clinical settings in relation to psychological outcomes have supported these underpinnings that positive coping strategies can improve psychological wellbeing, while negative coping strategies decrease psychological wellbeing (Brissette et al., 2002; Susan Folkman et al., 1993; Haynes \& Love, 2004). Specifically for construction workers Haynes and Love (2004) reported that project managers experienced similar stressors, but only those with positive coping strategies reported better psychological wellbeing. The second study thus aims to answer:

$\mathrm{RQ}_{2}$ : What is the relationship between daily stressors, coping strategies adopted and psychological outcomes (depression, anxiety and stress) for construction workers? (Study 2)

On the basis of confirmatory research, it is hypothesized for Study 2 that those strategies with a proactive or adaptive coping style will be negatively related psychological distress and, maladaptive coping styles (such as avoidance strategies) will be positively related psychological distress. More specifically, it is hypothesized that

$H_{1}$ : Adaptive coping strategies will negatively relate to (decrease) symptoms of depression, anxiety and stress $H_{2}$ : Maladaptive strategies will positively relate to (increase) symptoms of depression, anxiety and stress. 
$H_{3}$ : Coping strategies (M-mediator: adaptive and maladaptive) will mediate the relationship between daily stressors (IV-independent variable) and psychological outcomes (DVs-dependent variables: depression, anxiety and stress).

\section{Study 1}

RQ1: Which daily stressors do Australian construction workers consider as their primary sources of stress?

\section{Design}

Q methodology is considered a hybrid method between qualitative and quantitative elements (Stenner \& Rogers, 2004) and is designed to explore the people’s own perspectives and opinions (Previte, Pini, \& Haslam-McKenzie, 2007). Drawing from factor analytic theory, the Q method was invented in 1935 by British physicist/psychologist William Stephenson (Brown, 1997). The aim of this method is to objectively investigate subjective issues (Robbins \& Krueger, 2000). Q has been applied outside the psychology field, such as communication and political science, behavioral and health sciences and controversial topics including pornography and religion (Cross, 2005).

The instrumental basis of Q methodology is the Q sort technique-self-directed process. Participants are asked to evaluate (or sort, known as Q sorting) a number of statements (i.e. Q set) along a continuum from ‘very like me’ to ‘very unlike me’. “The data from $Q$ methodology are literally what participants make of a pool of items germane to the topic of concern, when asked to rank them" [(Stainton \& Rogers, 1995), p. 180]. Perceptions about construction work conditions are often captured by attitudinal surveys using Likert Scale - a scale used to represent people's attitudes to a topic, for example $1=$ totally disagreed and 5 totally agreed. The surveys are more structural where Q methodology is more functional (Capdevila \& Lazard, 2008) because it focuses on the demographic information (e.g. socioeconomic status and gender) and thus focuses on standard deviation values and 
Eigenvalues for generalizability. The Q method is not interested in generalizability (and thus could be a limitation for this approach), but rather focuses on the spectrum of individuals' opinions on a topic. This means the typical survey analysis addresses a population of people; the Q method is to present a population of viewpoints (Karim, 2001).

Parting from traditional surveys used in construction research in relation attitude and behaviors (e.g. Ng \& Chang, 2017; Love, Edwards \& Irani, 2010), Q methodology is deemed to be an appropriate technique to allow construction workers express their voices. It therefore can be seen that it has direct application in engineering and construction literature.

\section{Procedure}

Q set generation. For the generation of the $\mathrm{Q}$ set (stress items) a collection of ‘heterogeneous items’ for sorting by participants was created (Watts \& Stenner, 2005). The development of the Q set is guided by the research question and thus allows participates to respond appropriately. An initial pool of 93-items was generated based on previous research, existing stress scales and anecdotal feedback to reflect the research question of "Which daily stressors do Australian construction workers consider as their primary sources of stress?” The items included statements from the daily hassles scale - revised (Holm \& Holroyd, 1992), stressors identified by Leung et al. (2015) in their Hong Kong studies, stressors identified for Australian construction managers (Haynes \& Love, 2004) and items from outcomes of qualitative focus group session with construction workers (Australian Institute for Suicide Research and Prevention, 2006). To avoid double-ups in similarly worded statements 25 items were removed resulting in 68 remaining items (Appendix 1). Limitations include the restriction of pre-determined statements which could contain bias statements and constrain 
participants to pre-selected items. This is overcome by pooling a large range of items from existing research, between 40-80 items is considered satisfactory (Watts \& Stenner, 2005).

Q sorting process. The Q sort process followed the recommendations outlined by Watts and Stenner (2005). The item pool for final sorting by the participants consisted of 68items with each statement rephrased into a personal statement for consistency. For example, the statement "Lack of opportunity for advancement" was rephrased as "I feel there is a lack of opportunity for advancement”. Items were numbered and printed individually on an index card $(7.6 \mathrm{~cm} \times 23.7 \mathrm{~cm})$ for manual sorting. Sorting was conducted in sub-groups consisting of up to five construction workers. Each worker was presented with a complete set of cards (randomly shuffled) and an A4 sheet with a blank 13-point Q sort pyramid (68 squares for each of the items ranging from -6 "agree least”, 0 "neutral” and +6 "agree most”) to write the corresponding item statement number in the Q pyramid (Watts \& Stenner, 2005).

To minimize the issue in relation to workers' literacy, a researcher was present in the room to clarify or answer questions as well as to guide participants on Q sorting steps. Participants were instructed to complete an initial sort of the cards into three piles of stressors which are of (1) most concern to them, (2) neutral/unsure/sometimes, and (3) stressors which are of least concern to them individually. Following this, participants selected two statements (from the "most concern" pile) that reflected the most important stressors to them, and were instructed to write the corresponding item numbers in the +6 column of the pyramid. This process was repeated, alternating between each side of the pyramid (most concern, and least concern) until all cards were sorted, and their corresponding numbers written into the Q sort pyramid. At the conclusion of the sorting process participants attended in a brief post-sorting discussion to double check that all statements were clearly understood and sorting reflected participants’ perspectives. Participants were also invited to add any other concerns, comments, or the process itself. These answers were noted by the researcher for later 
evaluation and for consideration during the interpretation process if required (Watts \& Stenner, 2005).

\section{Participants}

A convenience sample of 18 construction workers (17 male) were recruited through advertising via the Construction, Forestry, Mining and Energy Union (CFMEU) and on a current construction worksite in Brisbane, Queensland using flyers and word of mouth. It is noted that Q methodology often involves small sample size. Therefore, small $n$ does not bias Q-methodology because the primary purpose is to identify a typology from a perspective intrinsic to the individual (i.e. primary stressors in the construction context) rather than testing hypothesis in a large population.

Participants were selected and recruited before starting work in the morning on their usual workday. All participants who volunteered were used for the study. The trades represented were: form workers or steel fixers $(n=4)$, general laborers $(n=4)$, machine operator ( $n=1)$, supervisor ( $n=1)$, union official $(n=1)$, plaster or tiler $(n=4)$, and worker listed as 'other' $(n=3)$. The average age of participants was 34 years $(S D=10.25)$, and have been working in the construction industry 11 years on average ( $S D=9.49)$. The tenure with current company was 5 years ( $S D=7.84)$ and usually worked for 5-6 days per week with average weekly hours of $48(S D=6.38)$.

\section{Results}

All analyses were conducted using PQMethod software version 2.35 (Atkinson, 1992). A varimax rotation was applied to all factors for preliminary analysis, as recommended by Watts and Stenner (2005). Each participant was subsequently viewed using PQROT 2.0 (a program within PQmethod, it is the default method for analysing q sorts within the program) by Zollorsch \& Schmolck using pre-flagging to view their fit within a factor. Participants who did not automatically load onto factor were manually flagged on the highest scoring 
factor to remain in the analysis (Schmolck, 2014). A final Q-analysis was performed after this procedure where eigenvalues, distinguishing statements (for inclusion in the stress scale), and items with non-significant values were examined. A detailed result can be found in Appendix 2. Table 1 summarizes the consensus stressors from construction workers' perspectives in ranked order from highest to lowest.

-------Table 1 about here---------

\section{Discussion}

This study aimed to contribute to existing literature by exploring the daily stressors relevant to the Australian construction labor workforce. This was conducted using Q methodology to sort and generate top consensus stressors, in order to understand those that are perceived as primary concerns $\left(\mathrm{RQ}_{1}\right)$. A three-factor solution with eigenvalues greater than one was used to identify the top consensus items, this also revealed a number of stressors which were not relevant for these construction workers.

Of the nonsignificant statements the item "there is inadequate safety equipment" directly contrasts findings by Leung et al. (2015). This supports that sources of stress identified in Hong Kong are different to those experienced by Queensland construction workers. However, when considering this, within the third factor, item 60 (I feel concerned about work-related accidents) indicates safety is still a concern, albeit not necessarily the equipment provided to workers. The item 'my pay is inadequate' was also not of concern. In Dhar (2011) construction workers were reported to receive low income, which contributed to stress. This further supports the notion that the international studies thus far on construction worker stress may not generalize to Queensland workers as they are not low income earners (Australian Bureau of Statistics, 2012).

Interestingly, “working too many hours” was also a nonsignificant finding which appears to contradict the first factor "concerns about time”, especially when the average 
number of working days reported was 5.7. This also contrasts with Haynes and Love (2004) where construction managers reported long hours as the second highest source of stress. Perhaps this may be an indicator that workers expect to work this many days, and could be considered an industry norm to work up to six days per week, or could be a reflection of the overtime paid as a result of working additional hours. Nonetheless, the current research did not conclude that long work hours did not impact on individual health and wellbeing. Nonsignficant results do not imply zero relationship, thus the authors believe that long work hours could somewhat impact on individual wellbeing. A lack of longitudinal data could be the current limitation and thus future research may examine the long-term effect of long working hours on workers' wellbeing by completing a follow up Q sort (to determine if the ranking of these stressors will still be the same). Further, larger sample size could be utilized to examine the effect of working long hours among construction workers.

Factor one “concerns about time” suggests workers are concerned about not having enough personal time and not being able to get things done. Though this conflicts with working on average 5.7 days per week, this may leave little time to integrate personal and home activities. This finding supports the qualitative data also reported by Australian Institute for Suicide Research and Prevention (2006) as a possible contributor to stress and suicidality. Haynes and Love (2004) reported this stressor as the third highest amongst construction managers, which suggests this may be an important theme for all construction workers, though it may be too early to draw inferences regarding this factor.

The factor two theme "financial concerns" align with qualitative studies conducted by Australian Institute for Suicide Research and Prevention (2006), particularly for concerns regarding owing money and financial management. There is little research exploring financial concerns and management for construction workers. This also suggests that 
financial management is an important issue worth further exploration and will be interesting to see if these findings will align with the next phase of this study.

Factor three theme "work concerns" demonstrates there are stressors directly related to the work environment which are potentially of concern to workers. Though Leung et al. (2015) included and explored interpersonal stressors in their construction studies, they were not rated highly among their workers. Leung et al. (2015) reported that these stressors were often highly correlated with issues concerning site safety and working conditions. Again, it is too early to draw inferences if this theme is rated highly for all construction workers. It should be highlighted that included in this theme was being concerned about one's diet, which does not fit entirely within issues surrounding work.

\section{Study 2}

$\mathrm{RQ}_{2}$ : What is the relationship between daily stressors, coping strategies and psychological outcomes for the construction labor workforce?

\section{Design}

The study design adopted was cross-sectional (due to the data being collected and analyzed from a population, or a representative subset, at a specific point in time) where the independent variable (IV) daily stressors were drawn from the first study. The dependent variables (DVs) operationalized as the psychological outcomes of (1) depression, (2) stress, and (3) anxiety. The design also included a coping mediator, which were classified as adaptive (active coping, planning, positive reframing, acceptance, humor, religion, emotional support, instrumental support) and maladaptive (self-distraction, denial, venting, substance use, behavioral disengagement, self-blame) based on previous research (Carver, 1997; Carver et al., 1993; Carver, Scheier, \& Weintraub, 1989; Meyer, 2001).

\section{Participants}


Ninety-one construction workers completed the survey as part of a convenience sample across two small commercial-residential construction sites in Brisbane, Queensland managed by a tier two construction company, of which $100 \%$ were male. The first construction site (site one) had completed construction phase and was in final fit-out stage $(n=50)$. The second construction site (site two) was nearing the end of construction phase and was commencing work on a second stage of construction $(n=41)$. Overall, 175 workers were invited to participate (site one $n=75$, site two, $n=100$ ) this is a $66 \%$ response rate for site one, and $41 \%$ for site two. The average age was 38 years ( $S D=10.22)$, and had been working in the construction industry 16 years on average $(S D=9.55)$. Tenure with current company was 3 years $(S D=3.28)$ and usually worked 5-6 days per week with average weekly hours of $47(S D=7.09)$.

\section{Measures}

A full list of measures can be found in an Appendix 3. This research measured daily stressors which were derived from Study 1. Respondents were asked how they coped with those daily stressors using The Brief-COPE Inventory (BCI) broadly categorizing as adaptive (planning, positive reframing, acceptance, humour, religion, using emotional support and using instrumental support) versus maladaptive coping (self-distraction, denial, venting, substance use, behavioural disengagement and self-blame). The respondents were also asked to report level of mental health based on the Depression Anxiety Stress scale (DASS-21, refer to Appendix 3). These adopted constructs have been intensively validated and used in various populations, including Australian sample. Nonetheless, the construct validity was performed using exploratory factor analysis (rather than confirmatory factor analysis due to limited sample size) prior to hypothesis testing. Demographic information such as age, sex (male/female), job site, marital status, years in the construction industry, years with current 
company and employment status (i.e. full time, part time, casual, self-employed) and employment type were used as control variables.

\section{Procedure}

The survey was administered across two separate commercial-residential construction work sites, over four days. Site one consisted of a two stage project with both stages in final fit out (and nearing completion). Site two also consisted of two stages, the first stage was near the end of the construction phase and in final fit out, with the second stage beginning construction (excavation was commencing). Participants were recruited during the morning, and were asked to complete the questionnaires printed double-sided on A4 paper using a pen/pencil. To avoid carry-over effects, the daily stressors, DASS-21 and BCI were printed separately and randomized before stapling together with the demographic information on the first page.

\section{Results}

The descriptive statistics for each of the scales and their reliability scores are reported in Table 2 and Table 3 shows the ranking of stressors among construction workers.

-----Table 2 and 3 about here-----

To test $H_{1}$ to $H_{3}$ mediated regression following the Baron and Kenny (1986) approach and Hayes (2016) process macro (version 2.16, add-on SPSS command which allows users employing an ordinary least squares or logistic regression-based path analytic framework for estimating direct and indirect effects in single and multiple mediator models for both parallel and serial) and SPSS version 23 were used. Table 4.1 to 4.4 summarize the results of regression analyses.

------Table 4.1 to 4.4 about here-----

Coping strategies were grouped into adaptive (active coping, planning, positive reframing, acceptance, humor, and instrumental support) and maladaptive (self-distraction, 
denial, venting, substance use, behavioral disengagement and self-blame). The mediator criterion will be supported if the effects of coping strategies remain significant after controlling for stressors (IV). If stressors are no longer significant when coping strategies (proposed mediators-M) are controlled, the finding supports full mediation. If IVs are still significant (i.e., both IV and M both significantly predict dependent variables), the finding supports partial mediation. The 'adaptive' coping strategies together explained $72.8 \%$ of variance in depression $\left[F(17,47)=7.38, M S E=23.83, p<.001, R=.85, R^{2}=.73\right]$; $55.3 \%$ of variance in anxiety $\left[F(17,47)=3.42, M S E=19.96, p<.001, R=.74, R^{2}=.55\right]$ and $57.3 \%$ of variance in stress $\left[F(17,47)=3.71, M S E=40.26, p<.001, R=.76, R^{2}=.57\right]$. While there was a large proportion of variance explained by the adaptive coping strategies together, the significant strategies' contributions were small. Humor uniquely contributed $6.4 \%$ of the variance in depression and $4.5 \%$ in anxiety. Acceptance uniquely contributed $7.4 \%$ of the variance in depression and $8 \%$ in anxiety (and only $4.5 \%$ in stress).

The 'maladaptive' coping strategies together explained $78.9 \%$ of variance in depression $\left[F(17,47)=10.37, M S E=18.40, p<.001, R=.89, R^{2}=.79\right]$, explained $63 \%$ of variance in anxiety $\left[F(17,47)=4.70, M S E=16.55, p<.001, R=.79, R^{2}=.63\right]$ and explained $60.3 \%$ of variance in stress $\left[F(17,47)=4.21, M S E=37.39, p<.001, R=.78, R^{2}=.60\right]$, supporting the third hypothesis. Again, there was a large proportion of variance explained by the maladaptive coping strategies together, the significant strategies contributions were small. Self-blame uniquely contributed 3.1\% of the variance in depression, 5.3\% in anxiety and $4.9 \%$ in stress. Behavioral disengagement uniquely contributed $6.8 \%$ of the variance in depression and 3.8\% in anxiety. Substance use uniquely contributed 5.4\% of variance in anxiety.

As the pathway between adaptive coping and psychological outcomes were positive instead of negative as the authors proposed, $H_{1}$ was not supported. A reversed effect will be 
discussed in a later section. $H_{2}$ was partially supported, two of the three maladaptive coping strategies were positively related to depression, stress and/or anxiety, supporting this hypothesis. However one maladaptive strategy (substance use) was negatively related to anxiety.

Drawing from meditation criterion as described prior, acceptance mediated the relationship between stressors and depression (Sobel test- a specialized test to determine whether the reduction in the effect of the independent variable, after including the mediator in the model, is a significant reduction: $z=3.00, p=.003$ ); anxiety (Sobel test: $z=2.53, p=$ .011 ); and stress (Sobel test: $z=2.05 p=.040$ ). While humor was significant for depression (Sobel test: $z=2.77, p=.006$ ), it approached significance for anxiety (Sobel test: $z=1.95, p$ $=.051$ ). Self-blame was significant for depression (Sobel test: $z=2.38, p=.018$ ), anxiety (Sobel test: $z=2.37, p=.018$ ) and stress (Sobel test: $z=2.22, p=.027$ ). Behavioral disengagement was significant for depression (Sobel test: $z=3.10, p=.002$ ) and anxiety (Sobel test: $z=1.99, p=.047)$. Substance use was significantly mediated on anxiety (Sobel test: $z=-2.06, p=.039$ ). As not all coping strategies were significantly mediated, thus $H_{3}$ was partially supported.

\section{Discussion}

Study 2 examined the relationships between daily stressors, coping strategies and psychological outcomes for construction workers. To further elaborate on $\mathrm{RQ}_{1}$ the main stressors in this study identified finances and lack of personal time as the highest rated stressors, similar to the findings in the first part of this study. The financial stressors included concerns about rising prices, future financial security and concerns about owing money. This potentially suggests that issues involving financial management may be contributing to the feelings of financial insecurity. Again these findings support the first part of this study and qualitative information gathered from Australian Institute for Suicide Research and 
Prevention (2006) indicating the association between financial management for construction workers needs further exploration.

Highest rated stressors from Study 2 also included a number of items in relation to little personal time. This was supported with construction workers reporting an average working week of 5.5 days, while working approximately 47 hours per week. This indicates the high work hours and long working weeks is a primary stressor for laborers and is potentially impacting on psychological outcomes. Work-life-balance is an important factor for many working Australians, highlighting the construction industry as a whole may need to review the practices of managing work-life-balance for construction workers in order to promote enhanced psychological wellbeing.

The hypotheses tests (mediation model) examined the relationships between stressors, coping and psychological outcomes of depression, stress and anxiety. The first hypothesis that daily stressors for workers will be perceived the same and have a positive relationship to the coping pathway for all adaptive and maladaptive coping strategies was supported. This finding supports Haynes and Love (2004) and the majority of stress literature, that negative stressors are perceived adversely and that this relationship may not change until resources are employed to attend to the situation (Lazarus \& Folkman, 1984, 1987).

The relationship between the coping strategies and psychological outcomes were mixed. There were only two significant adaptive mediators. Acceptance was significantly and positively related to depression, stress and anxiety, while humor was significantly and positively related to only depression and approached significance for anxiety, which could be considered counter-intuitive. This is in contrast to the majority of research suggesting adaptive styles of coping decrease psychological distress, and indicates these two strategies are unhelpful for construction workers. To explore this finding further, the questions used on the BCI were examined. Although the BCI has been widely validated and used to measure 
copings strategies, there is a possibility that the questions may have not tapped into this construct appropriately. The acceptance coping questions "accepting this has happened" and "learning to live with it" appear on face value to indicate defeat rather than using acceptance as a positive growth mechanism (Linley \& Joseph, 2004). Alternatively, individuals may think that they could accept the situation, but unconsciously they may not, and thus impacts on psychological health (which is caused by cognitive conflict). For humor, the questions do not elaborate on which type of humor is used. Studies involving humor as a coping mechanism indicate different types of humor (positive or negative) can impact differently on emotional outcomes (Samson \& Gross, 2012). Future studies could explore the different types of humor and its impact on mental health for construction workers.

For maladaptive coping, self-blame was positively related to depression, anxiety and stress, while disengagement was positively related to depression and anxiety. These findings are consistent with other literature on maladaptive coping and its relationship with negative outcomes. Substance use was related to decreases in anxiety, which did not support the hypothesis. One possible reason for this finding may be that workers are engaging in substance use to reduce anxiety short-term. Kushner, Abrams, and Borchardt (2000) found that substance use, particularly alcohol was a common short-term strategy used for reducing anxiety. It should be noted that Wilhelm et al. (2004) suggested there are implications for the engagement of substance use for coping in relation to suicide ideation. Furthermore, alcohol use is common in male-dominated industries and this has long-term health and wellbeing implications (Roche et al., 2015). This indicates that the use of substances for anxiety reduction short-term and its long-term impact on psychological wellbeing is an area which could be further explored in this demographic.

Overall the there was partial mediation for adaptive strategies for depression and stress, full mediation for anxiety, and full mediation for all of the maladaptive mediators $\left(\mathrm{H}_{3}\right)$. There 
are many biopsychosocial factors underpinning suicide, making it a complex phenomenon to fully understand. This study may provide insight into the future exploration of additional and alternative explanations beyond psychological distress underpinning these differences reported by Milner et al. (2014). A caveat exists however, whereby this study failed to detect any significant individual adaptive strategies for reducing psychological distress. Further research may benefit from seeking to understand the coping mediators which may promote psychological wellbeing for this demographic.

\section{Conclusion}

The practical implications of this study provide insight into stressors and the coping mechanisms adopted by construction workers which lead to increased feelings of psychological distress. For example, the highest rated stressors included low personal time combined with evidence supporting long working weeks (5.7 days Study 1; 5.5 days Study 2) and long hours supports the impact this is having on workers. Interestingly, the common themes for financial concerns and lack of time continued through from Study 1 to Study 2. This contributes to a body of empirical evidence suggesting these issues are important to construction workers, supporting calls for changes to industry to re-evaluate the work-lifebalance for construction laborers (Australian Institute for Suicide Research and Prevention, 2006).

Substance use (particularly alcohol) is prevalent within the construction industry which is heightened by a culture of strong drinking norms (Roche et al., 2015). A study on construction laborers in Australia indicated a high prevalence of risky alcohol use (Biggs \& Williamson, 2013). This combined with the potential of a short-term relief versus long-term health complications warrants further attention both by researchers and industry. Particularly into the investigations into the practical development of a workplace health promotion programs designed at targeting alcohol consumption and promoting positive coping strategies 
to further support good mental health. While no indication was given for the strategies that reduce psychological distress (except substance use for anxiety), attention towards teaching strategies which actively address the situation in a problem-solving manner (rather than accepting, or making jokes about the problem) may assist workers to engage in coping strategies that have the potential to reduce psychological distress.

The workplace offers a unique opportunity to assist with the reduction of psychological distress (e.g. depression) to promote wellbeing and increase productivity for its workforce (Tan et al., 2014). The use of suicide awareness and help-seeking programs such as Mates in Construction have demonstrated to be effective methods for increasing awareness, however the impact on its ability to reduce suicide rates for construction workers remains unclear (Gullestrup et al., 2011; Martin, Swannell, Milner, \& Gullestrup, 2016). Combining these programs with workplace health promotion programs on substance use, financial management identification, appropriate coping mechanisms and stress reduction presents an additional practical application for helping to improve psychological wellbeing in order to assist in targeting the high rates of suicide amongst the construction labor workforce.

\section{Limitations and Future Directions}

There are many limitations to this study, in particular the low sample size, which had implications on the analyses for the second phase of this study, particularly with the large number of control, mediator and dependent variables. Additionally, sampled here was a convenience sample of a narrow sub-sample of construction workers recruited from the same principal contractor on two small commercial residential projects, which may not be representative of the entire construction labor workforce. Also both the sites were in final fitout stage (with a second stage of construction commencing on site two). This is generally considered a winding down phase which may have impacted on the stress and wellbeing levels of the workforce. Furthermore, all participants in Study 2 were men, although 
construction is a typically a male dominated industry, this does limit the generalizability of the findings to Queensland male commercial-residential construction workers. Despite this, the study still provides insight into the stressors and coping relationships and psychological outcomes which are important first steps for understanding their relationship with psychological wellbeing for the labor workforce.

Secondly, the daily stressors for construction workers constructed adopted the use of Q sort to obtain a list of high consensus statements. This approach to the use of Q methodology was adopted due to time constraints for identifying relevant stressors for this demographic as one method to assist with developing a valid scale for use. While Q methodology provides insightful details regarding a construct under investigation Watts and Stenner (2005) advise analysis of both high and low consensus statements can provide rich contextual information on the topic. Unfortunately analysis the low consensus statements was not a primary purpose of this study, it is acknowledged this rich detail is missing and subsequently a limitation of the study. Future studies may benefit from refining the daily stressors for construction workers and further validation through focus groups and factor analysis with a large and more diverse sample of construction workers to provide a rigorous, scientific and empirically valid contribution to fully understand the unique stressors faced by construction workers.

Thirdly, the cross-sectional nature of this study limits the ability to measure coping changes over time and across different situations. There is the potential for different stressors to induce different coping mechanisms which may not be evident from a cross-sectional study. The generalizability may be limited due to the use of convenient sampling method. Nonetheless, the current study is explorative in nature, and this convenience sampling technique may prove to be effective during exploration stage of the research area. Future research can further expand the current finding for larger population, using randomized sample method. Additionally, although the mediation model was based on the stress-coping 
theory, there is the possibility of a bi-directional or reciprocal relationship of the stress coping relationship due to the study design. Future research should consider designing longitudinal and/or manipulation studies to fully investigate the coping relationship in this demographic.

The study also used self-report data, there may have been responder bias impacting these findings. The DASS-21 is a tool used to gauge the current level of psychological wellbeing. While it may not be possible to include every control variable, perhaps controlling for an already diagnosed mental health condition may have an impact on these findings and would have been an ideal variable to include in hindsight. It is also noted there were low coping means across all of the sub-scales. Perhaps this coping measure was not relevant to this demographic, a different coping measure may also be worth investigating. The BCI was selected as it was one of the shortest measures and was one that included a measure of substance use, which was identified by Vijayakumar et al. (2011) as a potential contributing factor to suicide. While the BCI is a widely used measure for coping, it appears the questions on humor and acceptance may have not been appropriate measures for this cohort.

Alternative measures, such as the Ways of Coping questionnaire includes less subscales (eight) however it contains 66 items (S. Folkman \& Lazarus, 1988). Its selection in this instance would have influenced the time needed to complete the survey.

Finally, there are many mediator and moderator variables identified in the literature which have potential impacts on these findings (e.g. personality). The time taken to complete the survey by workers was considered an important factor for this study, therefore the survey items were limited to stress, coping and psychological wellbeing.

Future research may benefit from further exploration of the stressors relevant to construction workers in Australia by further refining stressors to explore the distinct factors (such as financial insecurity and lack of time) to generalize these implications on wellbeing for laborers. Additionally, the short and long-term health and psychological implications of 
substance use and its relationship with anxiety is worth further exploration. Specifically, is the substance use related to short-term self-treatment in reductions of anxiety, which substances are in use, and are there any other contributing factors which are increasing the likelihood of the engagement in substance use as a coping strategy for anxiety reduction. As this study did not find any significant adaptive coping mediators, future research exploring different forms of adaptive coping strategies using alternative measures to the BCI in a large and more representative sample may provide insight into the coping strategies being used to assist with reducing psychological distress. 


\section{Appendix 1: The Complete Set of Statement Items used in Q Sort in Their Rephrased}

\section{Form}

\begin{tabular}{|c|c|}
\hline & Item \\
\hline 1. & $\begin{array}{l}\text { I’ve been concerned about inner } \\
\text { conflicts }\end{array}$ \\
\hline 2. & I've felt conflicted over what to do \\
\hline 3. & I have had regrets over past decisions \\
\hline 4. & I've felt an inability to express myself \\
\hline 5. & I experienced a fear of rejection \\
\hline 6. & $\begin{array}{l}\text { I experienced trouble making } \\
\text { decisions }\end{array}$ \\
\hline 7. & $\begin{array}{l}\text { I feel as though I don't see enough } \\
\text { people }\end{array}$ \\
\hline 8. & $\begin{array}{l}\text { I have troubling thoughts about my } \\
\text { future }\end{array}$ \\
\hline 9. & $\begin{array}{l}\text { I feel I don't have enough personal } \\
\text { energy }\end{array}$ \\
\hline 10. & I have concerns about getting ahead \\
\hline
\end{tabular}

Source

Holm and Holroyd (1992)

Holm and Holroyd (1992)

Australian Institute for Suicide and

Research Prevention (2006)

Haynes and Love (2004)

Holm and Holroyd (1992)

Holm and Holroyd (1992)

Holm and Holroyd (1992)

Holm and Holroyd (1992)

Australian Institute for Suicide and Research Prevention (2006)

Holm and Holroyd (1992)

Australian Institute for Suicide and Research Prevention (2006)

Holm and Holroyd (1992)

Holm and Holroyd (1992)

Australian Institute for Suicide and Research Prevention (2006)

Holm and Holroyd (1992)

11. I feel like I am wasting time

12. I don't have enough money for everyday living

13. I have concerns about owing money

14. I am concerned about my financial security

15. I don't have enough money for health care

16. I have concerns about getting credit

17. I feel concerned about property, investments or taxes

18. I have too many things to do

Holm and Holroyd (1992)

Holm and Holroyd (1992)

Holm and Holroyd (1992)

Australian Institute for Suicide and Research Prevention (2006)

Holm and Holroyd (1992)

Holm and Holroyd (1992)

Holm and Holroyd (1992)

Holm and Holroyd (1992)

Australian Institute for Suicide and Research Prevention (2006)

Holm and Holroyd (1992)

Dhar (2011)

19. I do not have enough time to do the

Holm and Holroyd (1992) things that need to be done

20. I have too many responsibilities

Australian Institute for Suicide and Research Prevention (2006)

Holm and Holroyd (1992)

21. I experienced not getting enough sleep

Holm and Holroyd (1992)

22. I don't get enough rest

Holm and Holroyd (1992) 
23. I've been experiencing too many interruptions

24. I don't have enough time for entertainment and recreation

25. I have too many social obligations

26. I don't spend enough time with family/friends

27. I have insufficient personal time

28. I feel concerned about meeting high standards

$29 . \quad$ I often experience noise

30. I have had problems getting along with fellow workers

31. I often work overtime

32. I feel there is a lack of opportunity for advancement

33. My fellow workers are not doing their jobs

34. I am often assigned to new or unfamiliar duties

35. There is inadequate support from my supervisor

36. I'm often dealing with crisis situations

37. I feel there is a lack of recognition for good work

38. I'm often performing tasks not in my job description

39. I feel there is inadequate or poor quality equipment

40. There is inadequate safety equipment provided

41. I am concerned about a gap break between one project to another

42. There is insufficient personnel to handle an assignment at my workplace
Holm and Holroyd (1992)

Australian Institute for Suicide and Research Prevention (2006)

Holm and Holroyd (1992)

Holm and Holroyd (1992)

Australian Institute for Suicide and

Research Prevention (2006)

Holm and Holroyd (1992)

Haynes and Love (2004)

Dhar (2011)

Australian Institute for Suicide and Research Prevention (2006)Holm and Holroyd (1992)

Haynes and Love (2004)

Australian Institute for Suicide and

Research Prevention (2006)

Holm and Holroyd (1992)

Dhar (2011)

Holm and Holroyd (1992)

Leung et al. (2015)

Holm and Holroyd (1992)

Australian Institute for Suicide and Research Prevention (2006)

Haynes and Love (2004)

Leung et al. (2015)

Leung et al. (2015)

Anecdotal/informal feedback

Leung et al. (2015)

Australian Institute for Suicide and Research Prevention (2006)

Dhar (2011)

Anecdotal/informal feedback

Leung et al. (2015)

Australian Institute for Suicide and

Research Prevention (2006)

Australian Institute for Suicide and Research Prevention (2006)

Leung et al. (2015)

Dhar (2011)

Leung et al. (2015)

Australian Institute for Suicide and Research Prevention (2006)

Leung et al. (2015)

Haynes and Love (2004) 
43. I feel there is a lack of participation in policy-making decisions

44. My pay is inadequate

45. I am often having to meet deadlines

46. I often cover work for another employee

47. I have poorly motivated co-workers

48. I experience conflict with other trades

49. I have a physically demanding job

50. I I am working too many hours

51. I often experience frequent interruptions at work

52. I have experienced problems with Enterprise Bargaining Agreements (EBAs)

53. My work requires excessive travel

54. I feel concerned over the parking situation

55. I do not receive enough job training

56. I often feel concerned about workrelated accidents

57. I experience concerns about traffic (to/from work)

58. I feel I have concerns about news events

59. I feel concerned about the rising prices of common goods

60. I often experience problems with my children

61. I feel concerned about yardwork or outside home maintenance

62. I often feel concerned about financing my children's education

63. I feel overloaded with family responsibilities

64. I often feel concerned about home maintenance (inside)

65. I have problems getting along with my spouse or partner
Leung et al. (2015)

Dhar (2011)

Australian Institute for Suicide and

Research Prevention (2006)

Haynes and Love (2004)

Haynes and Love (2004)

Haynes and Love (2004)

Australian Institute for Suicide and Research Prevention (2006)

Dhar (2011)

Australian Institute for Suicide and Research Prevention (2006)

Haynes and Love (2004)

Anecdotal/informal feedback

Anecdotal/informal feedback

Australian Institute for Suicide and Research Prevention (2006)

Dhar (2011)

Anecdotal/informal feedback

Anecdotal/informal feedback

Leung et al. (2015)

Australian Institute for Suicide and Research Prevention (2006)

Holm and Holroyd (1992)

Holm and Holroyd (1992)

Australian Institute for Suicide and Research Prevention (2006)

Holm and Holroyd (1992)

Holm and Holroyd (1992)

Holm and Holroyd (1992)

Australian Institute for Suicide and Research Prevention (2006)

Holm and Holroyd (1992)

Holm and Holroyd (1992)

Australian Institute for Suicide and Research Prevention (2006) Holm and Holroyd (1992) 


\begin{tabular}{|c|c|c|}
\hline 66. & $\begin{array}{l}\text { I feel concerned about my physical } \\
\text { health }\end{array}$ & $\begin{array}{l}\text { Holm and Holroyd (1992) } \\
\text { Dhar (2011) }\end{array}$ \\
\hline 67. & $\begin{array}{l}\text { I feel concerned about my mental } \\
\text { health }\end{array}$ & $\begin{array}{l}\text { Australian Institute for Suicide and } \\
\text { Research Prevention (2006) }\end{array}$ \\
\hline 68. & I feel concerned about my diet & Anecdotal/informal feedback \\
\hline
\end{tabular}

Appendix 2: Q sorting results

The initial maximum (eight-factor) solution contained three-factors with eigenvalues greater than one. In examining the distinguishing statements for the factors, only a few items (up to three) were loading onto each factor. Many of the distinguishing statements contained negative values indicating these items were least concerning for construction workers. As the purpose of the Q sort was to obtain high (or positive Q sort values) for the stress scale, further analyses with fewer factors was conducted. This was conducted on a three-factor solution where the eigenvalues greater than one, and a four-factor solution was also examined as the eigenvalue greater than one rule may be considered arbitrary (Watts \& Stenner, 2005).

The three and four-factor solutions were assessed using the top three consensus values of $+6,+5$ and +4 . The four-factor distinguishing statements contained 18 statements (two of these statements were observed to repeat across two different factors), while the three-factor solution contained 21 statements (with no items repeating across factors). Many of the items contained in the four-factor solution were consistent with the three-factor solution, with the exception of five statements; "I have had regrets over past decisions”; "I have troubling thoughts about my future”; “I experienced not getting enough sleep”; “I don’t get enough rest" and "there is inadequate support from my supervisor". As the purpose of the Q sort was to understand and obtain a list of relevant stressors to create a construction worker stressor scale, the three-factor solution was selected due to a larger number of items, which also contained the majority of those items included in the four-factor solution, with 10 additional statements not included in the four-factor solution. 
For the three-factor solution, one participant required manual flagging onto a factor, with each of the final factors containing six Q sorts. A final examination of the nonsignificant statements across factors revealed a total of 12 non-significant statements including "there is inadequate safety equipment provided"; "I am working too many hours" and "my pay is inadequate" meaning these items were consistently not a concern for construction workers.

Appendix 3: Measurement

Daily stressors for construction workers. The daily stressors (21 items) developed from the study one was used. Items were scaled for consistency with the other measures used in this study using a 4-point scale where $0=$ did not apply to me at all, $1=$ applied to me some degree, or some of the time, 2 = applied to me a considerable degree, or a good part of the time, and 3 = applied to me very much, or most of the time. There were no reversal of items, and participants were asked to rate which applied to them over the past week. Missing data was permitted for two or more items for this scale for consistency with the DASS-21.

Depression Anxiety Stress scale, 21-item (DASS-21). The DASS-21 is a 21-item self-report measure assessing individual negative affective states for depression, anxiety and stress, and is a shortened version of the full scale 42 -items. The DASS-21 contains seven items on each of the three sub-scales of depression, anxiety and stress with no reversal of questions. The items are measured on a 4-point scale where $0=$ did not apply to me at all, $1=$ applied to me some degree, or some of the time, 2 = applied to me a considerable degree, or a good part of the time, and 3 = applied to me very much, or most of the time. Each participant is asked rate each statement which applied to them over the past week. Samples and scale reliability for the items are depression "I felt I had nothing to look forward to" ( $\alpha=$ $.94)$, anxiety "I felt I was using a lot of nervous energy" $(\alpha=.87)$ and stress "I found myself getting agitated” $(\alpha=.91)$. Depression measures symptoms of dysphoria, hopelessness and 
self-depreciation. Anxiety measures symptoms of autonomic arousal, subjectiveness of the anxiety experience. Stress measures symptoms of tension, impatience and irritability (Antony, Bieling, Cox, Enns, \& Swinson, 1998; P. F. Lovibond, 1998; S. H. Lovibond \& Lovibond, 1995). The DASS-21 was found to have high convergent validity with other similar psychological outcome scales (Henry \& Crawford, 2005). It is recommended when using the DASS-21 that the scores are doubled to reflect that of the full scale measure with one missing data point allowed per scale (S. H. Lovibond \& Lovibond, 1995).

The Brief-COPE Inventory (BCI). The BCI is a 28-item self report measure assessing individual behavioral and cognitive responses to stressors, and is a shortened version of the COPE inventory (Carver et al., 1989). The BCI contains 14 sub-scales of different coping approaches, with each item measured on a 4-point Likert scale where $0=I$ haven't been doing this at all, 1 = I've been doing this a little bit, 2 = I've been doing this a medium amount, and 3 = I've been doing this a lot with no reversal questions. Each participant is asked to rate how much the statement applied to them over the past week.

Adaptive coping, planning, positive reframing, acceptance, humor, religion, using emotional support and using instrumental support are considered adaptive coping styles and are generally related to positive psychological outcomes and wellbeing. In contrary, selfdistraction, denial, venting, substance use, behavioral disengagement and self-blame are considered maladaptive coping styles and are generally related to poorer psychological wellbeing (Carver, 1997; Carver et al., 1993; Carver et al., 1989; Meyer, 2001). However, it is suggested that researchers are free to use the scale as needed including the minor adaptation of instructions, and the recommendation of performing a factor analysis to determine factors relevant to the sample studied. Previous studies using the BCI have omitted participants from the sub-scale for one point of missing data (Tharaldsen \& Bru, 2011). Therefore each of the 14 sub-scales will be calculated allowing for one missing data point, 
the only adaptation to the instructions was for consistency with the DASS-21 and daily stressors for experiences in coping limiting to the past week (Carver, 1997; Carver et al., 1989).

\section{Data Availability Statement}

Data generated or analyzed during the study are available from the corresponding author by request. Information about the Journal's data sharing policy can be found here: http://ascelibrary.org/doi/10.1061/\%28ASCE\%29CO.1943-7862.0001263

\section{References}

Antony, M. M., Bieling, P. J., Cox, B. J., Enns, M. W., \& Swinson, R. P. (1998). Psychometric properties of the 42-item and 21-item versions of the Depression Anxiety Stress scales in clinical groups and a community sample. Psychological Assessment, 10(2), 176-181.

Atkinson, J. R. (1992). Q method (computer software program). Kent, OH: Computer Center, Kent State University. Retrieved from http://schmolck.userweb.mwn.de/qmethod/webq/ Australian Bureau of Statistics. (2012). 1301.0 - Year book Australia, 2012. Employment in Australian industry. Retrieved from http://www.abs.gov.au/ausstats/abs@.nsf/Lookup/by\%20Subject/1301.0 2012 Main\% 20Features Employment\%20in\%20Australian\%20Industry 241

Australian Bureau of Statistics. (2015). Labour force, Australia, detailed, quarterly, Nov 2015. Retrieved from http://www.abs.gov.au/AUSSTATS/abs@.nsf/DetailsPage/6291.0.55.003Nov\%202015 ?OpenDocument 
Australian Institute for Suicide Research and Prevention. (2006). Suicide in Queensland's commercial building and construction industry. Brisbane, Australia, Institute for Suicide Research and Prevention.

Baker, J. P., \& Berenbaum, H. (2007). Emotional approach and problem-focused coping: A comparison of potentially adaptive strategies. Cognition and Emotion, 21(1), 95-118.

Baron, R. M., \& Kenny, D. A. (1986). The moderator-mediator variable distinction in social psychological research: Conceptual, strategic, and statistical considerations. Journal of Personality and Social Psychology, 51(6), 1173-1182.

Beehr, T. A., \& Glazer, S. (2005). Organizational role stress. In J. Barling, E. K. Kelloway, \& M. R. Frone (Eds.), Handbook of work stress. Thousand Oaks, California: Sage Publications Inc.

Biggs, H., \& Williamson, A. (2013). Reducing the risk of alcohol and other drugs in construction: An Australian assessment, New Developments in Structural Engineering and Construction, Electronic version doi:10.3850/978-981-07-5354-2_CS-14-255.

Bowen, P., Edwards, P., \& Lingard, H. (2013). Workplace stress experienced by construction professionals in South Africa. Journal of Construction Engineering and Management, 139(4), 393-403.

Bowen, P., Edwards, P., Lingard, H., \& Cattell, K. (2014). Workplace stress, stress effects, and coping mechanisms in the construction industry. Journal of Construction Engineering and Management, 140(3), 04013059.

Bowen, P., Govender, R., Edwards, P., \& Cattell, K. (2014). Workplace stress in the construction industry: An explanatory model. Paper presented at the 30th Annual ARCOM Conference (Association of Researchers in Construction Management), Portsmouth, UK. https://researchbank.rmit.edu.au/view/rmit:28588. 
Brissette, I., Scheier, M. F., \& Carver, C. S. (2002). The role of optimism in social network development, coping, and psychological adjustment during a life transition. Journal of Personality and Social Psychology, 82(1), 102-111.

Carver, C. S. (1997). You want to measure coping but your protocol's too long: Consider the brief COPE. International Journal of Behavioral Medicine, 4(1), 92-100.

Carver, C. S., Pozo, C., Harris, S. D., Noriega, V., Scheier, M. F., Robinson, D. S., . . Clark, K. C. (1993). How coping mediates the effect of optimism on distress: A study of women with early stage breast cancer. Journal of Personality and Social Psychology, 65(2), 375-390.

Carver, C. S., Scheier, M. F., \& Weintraub, J. K. (1989). Assessing coping strategies: A theoretically based approach. Journal of Personality and Social Psychology, 56(2), 267-283.

Cheng, C., Cheung, S.-f., Chio, J. H.-m., \& Chan, M.-p. S. (2013). Cultural meaning of perceived control: A meta-analysis of locus of control and psychological symptoms across 18 cultural regions. Psychological Bulletin, 139(1), 152-188.

Chronister, J., Johnson, E., \& Lin, C.-P. (2014). Coping and rehabilitation: Theory, research and measurement. In E. Da Silva Cardoso, J. A. Chronister, \& F. Chan (Eds.), Understanding psychosocial adjustment to chronic illness and disability: A handbook for evidence-based practitioners in rehabilitation. New York, NY: Springer Publishing Company.

Connor-Smith, J. K., \& Flachsbart, C. (2007). Relations between personality and coping: A meta-analysis. Journal of Personality and Social Psychology, 93(6), 1080-1107. 
Dhar, R. L. (2011). Leisure as a way of coping with stress: An ethnographic study of the lowincome construction workers. Leisure/Loisir, 35(3), 339-360.

Dijkers, M. (1997). Quality of life after spinal cord injury: A meta-analysis of the effects of disablement components. Spinal Cord, 35(12), 829-840.

Doran, C. R., Ling, R., \& Milner, A. (2015). The economic cost of suicide and non-fatal suicidal behaviour in the Australian construction industry by state and territory. Hunter Medical Research Institute Retrieved from http://www.matesinconstruction.org.au/flux-content/mic-2013/pdf/Cost-of-suicidein-construction-industry-final-report.pdf.

Folkman, S., Chesney, M., Pollack, L., \& Coates, T. (1993). Stress, control, coping, and depressive mood in human immunodeficiency virus-positive and -negative gay men in San Francisco. The Journal of Nervous and Mental Disease, 181(7), 409-416.

Folkman, S., \& Lazarus, R. S. (1988). Manual for the Ways of Coping scale. Palo Alto, CA: Consulting Psychologists Press.

Goldenhar, L. M., Williams, L. J., \& Swanson, N., G. (2003). Modelling relationships between job stressors and injury and near-miss outcomes for construction labourers. Work \& Stress, 17(3), 218-240.

Gullestrup, J., Lequertier, B., \& Martin, G. (2011). MATES in Construction: Impact of a multimodal, community-based program for suicide prevention in the construction industry. International Journal of Environmental Research and Public Health, 8(11), 4180-4196.

Hayes, A. F. (2016). The PROCESS macro for SPSS and SAS (Version 2.16). Retrieved from http://processmacro.org/download.html 
Haynes, N. S., \& Love, P. E. D. (2004). Psychological adjustment and coping among construction project managers. Construction Management and Economics, 22(2), 129-140.

Henry, J. D., \& Crawford, J. R. (2005). The short-form version of the Depression Anxiety Stress scales (DASS-21): Construct validity and normative data in a large nonclinical sample. The British Journal of Clinical Psychology, 44(2), 227-239.

Herbert, T. B., \& Cohen, S. (1993). Stress and immunity in humans: A meta-analytic review. Psychosomatic medicine, 55(4), 364-379.

Holm, J. E., \& Holroyd, K. A. (1992). The daily hassles scale (revised): Does it measure stress or symptoms? Behavioral Assessment, 14(3-4), 465-482.

Iacuone, D. (2005). "Real men are tough guys": Hegemonic masculinity and safety in the construction industry. Journal of Men's Studies, 13(2), 247-261.

Jacobsen, H. B., Caban-Martinez, A., Onyebeke, L. C., Sorensen, G., Dennerlein, J. T., \& Reme, S. E. (2013). Construction workers struggle with a high prevalence of mental distress, and this is associated with their pain and injuries. Journal of occupational and environmental medicine / American College of Occupational and Environmental Medicine, 55(10), 1197-1204.

Jamal, M. (1984). Job stress and job performance controversy: An empirical assessment. Organizational Behavior and Human Performance, 33(1), 1-21.

Krohne, H. W. (1996). Individual differences in coping. In M. Zeidner \& N. S. Endler (Eds.), Handbook of coping: Theory, research, applications. Canada: John Wiley \& Sons, Inc.

Krohne, H. W. (2001). Stress and coping theories. In P. B. Baltes (Ed.), International Encyclopaedia of the Social \& Behavioral Sciences (pp. 15163-15170). Oxford: Pergamon. 
Kushner, M. G., Abrams, K., \& Borchardt, C. (2000). The relationship between anxiety disorders and alcohol use disorders: A review of major perspectives and findings. Clinical Psychology Review, 20(2), 149-171.

Lazarus, R. S. (1993). Coping theory and research: Past, present, and future. Psychosomatic Medicine, 55(3), 234-247.

Lazarus, R. S., \& Folkman, S. (1984). Stress, appraisal and coping. New York, NY: Springer Publishing Company, Inc.

Lazarus, R. S., \& Folkman, S. (1987). Transactional theory and research on emotions and coping. European Journal of Personality, 1(3), 141-169.

Leung, M. Y., Chan, I. Y. S., \& Cooper, C. L. (2015). Sources of stress affecting construction personnel. Chichester, UK: John Wiley \& Sons, Ltd.

Leung, M. Y., Chan, I. Y. S., \& Yu, J. (2012). Preventing construction worker injury incidents through the management of personal stress and organizational stressors. Accident Analysis \& Prevention, 48, 156-166.

Leung, M. Y., Chan, Y. S., Chong, A., \& Sham, J. F.-C. (2008). Developing structural integrated stressor-stress models for clients’ and contractors’ cost engineers. Journal of Construction Engineering and Management, 134(8), 635-643.

Leung, M. Y., Chan, Y. S., \& Olomolaiye, P. (2008). Impact of stress on the performance of construction project managers. Journal of Construction Engineering and Management, 134(8), 644-652.

Leung, M. Y., Chan, Y. S., \& Yuen, K.-W. (2010). Impacts of stressors and stress on the injury incidents of construction workers in Hong Kong. Journal of Construction Engineering and Management, 136(10), 1093-1103. 
Leung, M. Y., Sham, J., \& Chan, Y. (2007). Adjusting stressors-job-demand stress in preventing rustout/burnout in estimators. Surveying and Built Environment, 18(1), $17-26$.

Leung, M. Y., Skitmore, M., \& Chan, Y. S. (2007). Subjective and objective stress in construction cost estimation. Construction Management and Economics, 25(10), 1063-1075.

Lingard, H., \& Turner, M. (2015). Improving the health of male, blue collar construction workers: A social ecological perspective. Construction Management and Economics, 33(1), 18-34.

.Linley, P. A., \& Joseph, S. (2004). Positive change following trauma and adversity: A review. Journal of Traumatic Stress, 17(1), 11-21.

LivingWorks. (2015). SafeTALK: Suicide alertness for everyone. Retrieved from https://www.livingworks.net/dmsdocument/574

Love, P. E. D., Edwards, D. J., \& Irani, Z. (2010). Work stress, support, and mental health in construction. Journal of Construction Engineering and Management, 136(6), 650658.

Lovibond, P. F. (1998). Long-term stability of depression, anxiety, and stress syndromes. Journal of Abnormal Psychology, 107(3), 520-526.

Lovibond, S. H., \& Lovibond, P. F. (1995). Manual for the depression anxiety stress scales (2nd ed.). Sydney, NSW: Psychology Foundation.

Martin, G., Swannell, S., Milner, A., \& Gullestrup, J. (2016). Mates in construction suicide prevention program: A five year review. Journal of Community Medicine \& Health Education, 6(4), 1-8.

McEwen, B. S. (1998). Stress, adaptation, and disease: Allostasis and allostatic load. Annals of the New York Academy of Sciences, 840(1), 33-44. 
Meyer, B. (2001). Coping with severe mental illness: Relations of the brief COPE with symptoms, functioning, and well-being. Journal of Psychopathology and Behavioral Assessment, 23(4), 265-277.

Milner, A. (2016). Suicide in the construction industry: Report by Deakin University for MATES in construction. Retrieved from Victoria, Australia:

http://micaus.bpndw46jvgfycmdxu.maxcdn-edge.com/wpcontent/uploads/2015/11/MIC-Annual-suicide-report-MIC-and-DeakinUniversity.pdf

Milner, A., Niven, H., \& LaMontagne, A. (2014). Suicide by occupational skill level in the Australian construction industry: Data from 2001 to 2010. Australian and New Zealand Journal of Public Health, 38(3), 281-285.

Mohr, D. C., Hart, S. L., Julian, L., Cox, D., \& Pelletier, D. (2004). Association between stressful life events and exacerbation in multiple sclerosis: A meta-analysis. $B M J$ : British Medical Journal, 328(7442), 731-731.

Muse, L. A., Harris, S. G., \& Feild, H. S. (2003). Has the Inverted-U theory of stress and job performance had a fair test? Human Performance, 16(4), 349-364.

Petrick, J. A., \& Rinefort, F. C. (2004). The challenge of managing China's workplace safety. Business and Society Review, 109(2), 171-181.

PricewaterhouseCoopers. (2014). The mentally healthy workplace alliance final report, March 2014. Retrieved from https://www.headsup.org.au/docs/defaultsource/resources/beyondblue_workplaceroi_finalreport_may2014.pdf?sfvrsn=6Roche, A. M., Lee, N. K., Battams, S., Fischer, J. A., Cameron, 
J., \& McEntee, A. (2015). Alcohol use among workers in male-dominated industries: A systematic review of risk factors. Safety Science, 78, 124-141

Roche, A. M., Lee, N. K., Battams, S., Fischer, J. A., Cameron, J., \& McEntee, A. (2015). Alcohol use among workers in male-dominated industries: A systematic review of risk factors. Safety Science, 78, 124-141.

Safe Work Australia. (2013). Work-related traumatic injury fatalities, Australia 2012. Retrieved from http://www.safeworkaustralia.gov.au/sites/SWA/about/Publications/Documents/811/ Traumatic-Injury-Fatalities-2012.pdf

Samson, A. C., \& Gross, J. J. (2012). Humour as emotion regulation: The differential consequences of negative versus positive humour. Cognition and Emotion, 26(2), 375-384.

Sawang, S., Oei, T. P., Goh, Y. W., Mansoer, W., Markhum, E., \& Ranawake, D. (2010). Confirmatory Factor Analysis of the Way of Coping Checklist-Revised (WCCL-R) in the Asian Context. Applied Psychology, 59(2), 202-219.

Schmolck, P. (2014). PQMethod manual. Retrieved from http://schmolck.userweb.mwn.de/qmethod/pqmanual.htm

Selye, H. (1950). Stress and the General Adaptation Syndrome. The British Medical Journal, 1(4667), 1383-1392.

Skinner, E. A., Edge, K., Altman, J., \& Sherwood, H. (2003). Searching for the structure of coping: A review and critique of category systems for classifying ways of coping. Psychological Bulletin, 129(2), 216-269.

Smith, C. A., \& Wallston, K. A. (1997). The 3 Ms: macro-analysis, micro-analysis and metaanalysis. Journal of Health Psychology, 2(2), 166-167. 
Tan, L., Wang, M.-J., Modini, M., Joyce, S., Mykletun, A., Christensen, H., \& Harvey, S. B. (2014). Preventing the development of depression at work: A systematic review and meta-analysis of universal interventions in the workplace. BMC Medicine, 12(1), 111.

Tharaldsen, K. B., \& Bru, E. (2011). Validation of the mindful coping scale. Emotional and Behavioural Difficulties, 16(1), 87-103.

Thoits, P. A. (1995). Stress, coping, and social support processes: Where are we? What next? Journal of Health and Social Behavior, 36(1), 53-79.

Vijayakumar, L., Kumar, M. S., \& Vijayakumar, V. (2011). Substance use and suicide. Current Opinion in Psychiatry, 24(3), 197-202.

Vilhjalmsson, R., Sveinbjarnardottir, E., \& Kristjansdottir, G. (1998). Factors associated with suicide ideation in adults. Social Psychiatry and Psychiatric Epidemiology, 33(3), 97-103.

Watts, S., \& Stenner, P. (2005). Doing Q methodology: Theory, method and interpretation. Qualitative Research in Psychology, 2(1), 67-91.

Wilhelm, K., Kovess, V., Rios-Seidel, C., \& Finch, A. (2004). Work and mental health. Social Psychiatry and Psychiatric Epidemiology, 39(11), 866-873.

Yung, L. M., Chan, Y.-S., \& Yu, J. (2009). Integrated model for the stressors and stresses of construction project managers in Hong Kong. Journal of Construction Engineering and Management, 135(2), 126-134 